\title{
TRUST AMONG CO-PRODUCERS OF PUBLIC SERVICES AND THE IMPACT OF TRANSPARENCY
}

\author{
Andrius Puksas ${ }^{1}$
}

\begin{abstract}
The co-production of public services as a process requires parties to cooperate in creating new or improved existing public services and in the delivery of these services. As any other social process, it is expected to be built on trust, benevolence and the balance of interests. Trust between cooperating parties, and between the parties and users of final co-production services is crucial. In other words, trust among stakeholders is expected. The potential benefits of co-production lie in the involvement of qualitatively different stakeholders, who to some extent are interested in the result and have the required resources (human resources, financial, know-how, etc.) to contribute. Together with obvious benefits, co-production as a process brings a challenging task to balance the different interests, expectations, demands and maintain trust among co-producers and the users of public services. The paper is based on a conceptual analysis and the analysis of scientific literature; no empirical data was analysed. It provides the definition and the main features of co-production, and analyses the impact of trust among the stakeholders and the role of transparency. Despite the fact that co-production can cover different areas, the article is limited to co-production of public services.
\end{abstract}

UDC Classification: 351. , DOI: https://doi.org/10.12955/pss.v1.71

Keywords: co-production; trust; public services; involvement, transparency.

\section{Introduction}

The increased amount of co-production based research reflects the growing importance of co-production as a process and of the demand to use it to meet the needs of society. Some researchers define coproduction as the voluntary or involuntary involvement of public service users in any of the design, management, delivery and/or evaluation of public services (Osborne et al., 2016). Voluntary involvement in co-production allows the assumption that the participants of this process are more likely to trust each other or have their own motivation to cooperate, which is higher than the attitude towards another party of cooperation. Involuntary involvement weakens such an assumption because of the nature of involvement and decreased or absent motivation of one of the co-producers.

Every party entering into cooperation has their own expectations (for instance, possible public or personal benefits, etc.), motivation, and demands. Despite the reasons and inner motivation being to cooperate in creating, improving or/and providing public services, the process is smoother when there is no conflict between the parties, and consensus or balance of interests is reached. The demand for specific public services and their quality comes from users and has a strong impact on the need for an appropriate services provider. For providers of public services, co-production is a powerful tool to check if users of public services are satisfied with their current (or demand new) services, trust the provider, and whether some will agree to collaborate to make services better, or design new ones.

The involvement of at least one public service user in the process of service creation, improvement or provision can motivate more users to cooperate as co-producers. In the case of a proper and cooperationfriendly environment, a massive spread of the phenomenon is possible. In some cases. it is possible to observe the development of a co-productive community. Such a development can lead to the consequent social and personal progress of the participants through citizens' competence, empowerment and renewed trust in their government (Vanleene \& Verschuere, 2018).

Co-production from the initial stage should be powered by trust; however, co-production is expected to reduce the democratic deficit and increase trust and transparency (Durose, 2011). The building or increasing of trust through co-production of public services has received the attention of a number of researchers, for instance, Fledderus (2015, 2018), Meijer (2016), Balliet \& Van Lange (2012), etc.

\section{Theoretical background}

The co-production of public services is a complex process, which can cover one or more stages of possible interaction between parties intent on cooperation. 'Co-production covers a number of different 'co-' stages where the involvement of current or potential public service users is possible, for example stages of 'co-design', 'co-management', etc.' (Puksas et al., 2019). Meijer (2016) notes that coproduction is a concept usually used to connote a change to a more collaborative relationship between citizens and government. It reflects the change in attitude from 'imposed services' to 'harmonized

\footnotetext{
${ }^{1}$ Mykolas Romeris University, Vilnius, Lithuania, andrius_puksas@mruni.eu
} 
services'. The outdated point of view that a public authority knows better than the users has turned into a process where users are invited to contribute to creating public value. Such a contribution is less likely in situations where the level of trust is low.

Practice showed that citizens can be involved in almost all areas they are interested in, including but not limited to crime control, healthcare, etc. The higher probability to expect the intention of users to cooperate is in sectors in which a particular potential co-producer as user - or people he/she cares for receive some sort of benefit, and where there is higher demand for improvement.

As mentioned above, co-production covers a number of 'co-' actions or stages, where citizens have the opportunity to become involved. One possible stage-based classification of co-production is coplanning, co-design, co-prioritisation, co-financing, co-managing, co-delivery, and co-assessment (Bovaird \& Loeffler, 2012). This classification covers stages of joint participation in after 'co-' mentioned activity. Taking into account that cooperation creates not only rights, but brings a considerable set of duties, another stage after co-assessment could be co-responsibility - which appears less often among the other 'co-'s. However, not all definitions of co-responsibility are similar. In one case it can mean that parties share responsibilities for their actions; in another - the cooperation should be socially responsive, etc. For instance, the Council of Europe describes co-responsibility as cooperation of multiple actors in order to achieve social well-being (Stott, 2018). However, such an abstract definition, taking into account the expectation that co-production aims to create public value, can be adopted for other stages.

The parties can start to cooperate from any stage and cooperate during one or more stages; however, the involvement from the co-planning or another earlier stage can bring some added value and determine the cooperation during further stages (Puksas, 2020). Cooperation makes sense while the parties trust each other and coordinate their activities, avoiding possible conflict or solving emerged conflicts peacefully. The concept of trust in its natural meaning appears in democracies where the public administration institutions are dependent on the attitude of citizens towards them. Trust is not unconditional and independent of the actions of public administration entities. Trust is a different matter in the conditions of other regimes. Co-production brings a new role for citizens, who from being passive beneficiaries of government activities, through participation become vital players in their success or failure (Sorrentino et al., 2018).

Trust should cover all related processes:

- deciding to choose co-production instead of other more traditional ways;

- choosing partners, negotiating with potential partners and agreeing to cooperate with them;

- believing that co-production with following partner or partners can lead to the desired results;

- sharing duties and responsibilities among the partners;

- cooperating at any stage;

- receiving trust from the end users in parties which were involved in cooperation, etc.

Only a few of the processes which require trust among stakeholders are listed above. The list cannot be finite. Trust creates a chain from those who are involved in producing public services to the end users of them.

Psychological research usually distinguishes the importance of trust in initiating, establishing and maintaining social relationships. 'Trust encourages the initiation of mutual cooperative relationships and results in greater relationship commitment and satisfaction, and broken trust may mark the demise of social relations' (Balliet \& Van Lange, 2012).

Every public administration institution has its own place and role in the provision of public services. Trust in an institution and the services it provides usually appears over time, assessing experience of interactions between the institution and users, and through the positive practices of the relevant institution. Previous failures, inflexibility in service provision and communication with users leads to additional efforts to restore confidence. However, trust can be not only the result of previous activities and actions, it can be given as credit for future activities.

\section{Trust through agreement on details of issue}

The role of trust and confidence is especially important because co-production is aimed not only to benefit the individual but is expected to produce public value. The role of trust emerges through the 
number of beneficiaries of public goods. Usually co-production appears where there is a need to add additional partners in order to solve some potential problem, such as a lack of resources to create or improve public services independently or a lack of information about the needs and expectations of citizens, etc. The choice of co-production is a first step in proving that there is no lack of trust in citizens' capacities.

Demand for new services or the improvement of existing ones usually arises from users of public services or potential users of requisite services. This could be a lack of such services or even dissatisfaction with services already provided. The actions should start from an analysis of perceived need.

As in any other social process where two or more actors are involved, co-production is not an aimless process but always result oriented. Agreeing on details should be among the first steps. The vision and expectations of parties should be refined, discussed and analysed. If there is confidence among potential co-producers, it is important to clearly define and understand the roles and duties in cooperation in order to avoid possible conflicts and misunderstandings. While there is a need to set clear rules, flexibility in cooperation should also be maintained.

A decision to invite citizens to co-produce has practical aspects - institutions receive a credit of confidence, a mechanism to make delivery of services more advanced, and in the case of failure, an excuse, because of the involvement of users in the co-production process. '(Local) governments embrace citizen engagement, as they consider it as a valuable way to overcome some real or perceived challenges they are confronted with like the need to make public service delivery more efficient, effective and democratic, and to restore trust in and satisfaction with government and politics' (Brandsen et al., 2018).

Agreement on details is also dependent on the stage partners' agreement to cooperate - in some stages it is enough to agree on one detail, in another stage - on another detail. For instance, agreeing on financial issues is more important before the co-financing stage starts. The success of cooperation at one stage is a precondition for possibly entering other stages. For parties it is important to agree and consider possible options, answering the question 'What if?'

Trust and confidence cover the predictability of possible actions and behaviour from another cooperating party. Agreement on issue-related details, assessing the risks and agreeing on possible conflict resolution options allows strengthening such predictability. Unpredictability usually appears where the parties are cooperating without a clear plan. Previous models of behaviour and previous practice are equally important.

\section{Trust and transparency}

A public administration institution is expected to conduct its actions toward users of its services efficiently, accountably, and transparently. Responsive actions should be without hidden benefits for particular small groups involved, and results should be widely available (at least for the significant part of society). Transparency can be ensured not only through information provision but also through other publicly oriented actions. 'The need for accountability, transparency and citizen involvement in the production/provision of public services and goods in SOCs is particularly important to avoid unethical forms of behaviour and to increase public value and interest' (Calabro, 2012).

The involvement of users of public services in a process where services are (or appear to be) improved also strengthens transparency. The possibility to monitor, act and be part of the process can lead to higher standards of public services and strengthen trust in institutions. A 'Nothing to hide' policy also shows that institutions are working fairly and ready to be more responsive. 'Increased transparency of government services can enable citizens to be "armchair auditors" and critically follow and assess the performance of public service organizations. Citizen monitoring can contribute to the performance of service organizations and also to increase public trust in these organizations' (Gasco-Hernandez \& GilGarcia, 2017).

The ways in which the services were created, developed, and delivered, together with other relevant information, should be publicly available. This allows assessing the quality of work of the institution involved: the nature of public institutions as public authorities is to serve the people.

It is important to take into account that some stages of co-production could be more sensitive and require a higher standard of trust. For instance, there is a high expectation that without a proper level of trust 
co-financing is almost impossible. The investment of funds is usually connected with some sort of risk. However, despite the risk, parties should have some sort of guarantee that funds will only be used for their intended purpose. Here, transparency and accountability are crucially important.

Clear and transparent rules, legal regulations and the absence of artificial barriers are among the most important preconditions to encourage co-production. However, even policies promoting co-production may be not enough. They will not automatically foster the trust of citizens in service delivery and in (local) government (Brandsen et al., 2018).

The requirement of transparency is not purely technical. Institutions should be responsive regarding any request concerning the services they provide or are planning to provide. Involvement and the opportunity to contribute (even if untaken) shows openness to the users of public services. It is important to open the space and remove the obstacles for co-producers of public services to make their contribution to the creation, development and provision of those services. Openness for cooperation could serve as proof that an institution has 'nothing to hide'. Even if the option is still unused, the possibility to choose it can strengthen trust.

Users of public services are usually more loyal to providers they trust and are satisfied with regarding their attitude to users and quality of services. A track record of cooperation and service provision is also important - previous experience brings a reason to trust, not to trust or to review the position concerning the relevant provider.

\section{The absence or loss of trust}

Co-production as a social process requires partners to work together; however, this does not automatically bring trust into the process. The reasons partners have to co-produce, their motives and expectations, could be different and not balanced - this emerges especially more sharply when the parties are not flexible and benevolent. An absence or loss of trust and confidence can appear between the stakeholders in different situations:

- previous experience does not allow a provider to be trusted anymore, or the level of trust is decreased;

- a provider does not express trust in citizens' capacities;

- there is miscommunication among the stakeholders;

- the provider is new and there is no reason to credit them with trust.

Taking into account that involvement in co-production can be voluntary or involuntary, initially it is especially important to maintain trust - if cooperation started through a person's volition, it can be terminated after the loss of trust or motivation.

Trust and confidence are not so crucial in the case where public services are essential, or there are no alternatives to such services. In such cases trust in a provider is not a decisive factor for users. Also, it changes less in the case where one party is dependent on another.

The absence of trust does not automatically mean that a provider is condemned. 'While government legitimacy is about citizen trust in government, trust in other citizens is a key question for the legitimacy of co-productive arrangements' (Meijer, 2016). It can work as motivator for co-production - allowing and inviting the user to contribute and restore trust.

\section{Conclusions}

The amount of co-production of public services-based research reflects the growing importance of coproduction. It allows for the creation or improvement of existing public services through the involvement of users of public services. However, the parties should be ready to balance their interests during the cooperation process. This comes from the fact that every party in co-production at different stages (planning, design, prioritisation, financing, managing, delivery, etc.), before entering into cooperation, has their own expectations, motivation, and demands. It is crucial to agree on all possible details of cooperation and other relevant issues before working together starts.

Cooperating parties should maintain trust in each other and have trust or credit of trust from the users of public services. Trust can be achieved through previous experiences and practices, and through attitudes towards the users of public services. Transparency and accountability can also contribute to the strengthening of trust. 
However, in some cases trust is not a prerequisite (public services are essential, there are no alternatives, etc.) but it can be achieved and strengthened if a public administration institution decides to be more open and responsive to users of public services. The users of public services are usually more loyal to the providers they trust and are satisfied with regarding their attitude to users and quality of services.

\section{References}

Balliet, D., \& Van Lange, P. A. M. (2012). Trust, Conflict, and Cooperation: A Meta-Analysis. Psychological Bulletin, 139 (5).

Bovaird, T., \& Loeffler, E. (2012). From engagement to co-production: The contribution of users and communities to outcomes and public value. Voluntas: International Journal of Voluntary and Nonprofit Organizations, 23 (4), 1119-1138.

Brandsen, T., Steen, T., \& Verschuere, B. (2018). Co-creation and co-production in public services. Urgent issues in practice and research. In book Co-production and co-creation. Engaging citizens in public services (ed. Brandsen, T., Steen, T., \& Verschuere, B.), Routledge Critical Studies in Public Management, 3-8.

Brandsen, T., Steen, T., \& Verschuere, B. (2018). How to encourage co-creation and co-production. Some recommendations. In book Co-production and co-creation. Engaging citizens in public services (ed. Brandsen, T., Steen, T., \& Verschuere, B.), Routledge Critical Studies in Public Management, 299-302.

Calabro, A. (2012). Co-production: an alternative to the partial privatization processes in Italy and Norway. In book New Public Governance, the Third Sector, and Co-Production (ed. Pestoff, V., Brandsen, T., \& Verschuere, B.), Routledge, $317-$ 336.

Fledderus, J. (2015). Building trust through public service co-production. International Journal of Public Management, 28(7), 550-565.

Fledderus, J. (2018). The effects of co-production on trust. In book New Public Governance, the Third Sector, and CoProduction (ed. Pestoff, V., Brandsen, T., \& Verschuere, B.), Routledge, 258-265.

Gasco-Hernandez, M., \& Gil-Garcia, J. (2017). Is it more than using data and technology in local governments: Identifying opportunities and challenges for cities to become smarter. UMKC Law Review, 85(4), 915-924.

Meijer, A. (2016). Co-production as a structural transformation of the public sector. International Journal of Public Sector Management, 29 (6), 596-611.

Osborne, S. P., Radnor, Z., \& Strokosch, K. (2016). Co-production and the co-creation of value in public services: a suitable case for treatment? Public Management Review, 18 (5), 639-653.

Puksas, A. (2020). The implication of motivation and role of user expectations in the co-production of public services. Contemporary Research on Organization Management and Administration, 8 (1), 19-30.

Puksas, A., Gudelis, D., Raišienė A. G., \& Gudelienė, N. (2019). Business, government, society and science interest in coproduction by relative evaluation using Google Trends. Management of organizations: systematic research, 81, 55-71.

Sorrentino, M., Sicilia, M., \& Howlett, M. (2018). Understanding co-production as a new public governance tool. Policy and Society, 37 (3), 277-293.

Stott, L. (2018). Co-production - enhancing the role of citizens in governance and service delivery. Technical Dossier No. 4 , Directorate General for Employment, Social Affairs and Inclusion. Retrieved from https://ec.europa.eu/esf/transnationality/filedepot_download/1145/1723

Vanleene, D., \& Verschuere, B. (2018). Co-production in community development. In book Co-production and co-creation. Engaging citizens in public services (ed. Brandsen, T., Steen, T., Verschuere, B.), Routledge Critical Studies in Public Management, 198-207. 